\title{
MTHFR gene A1298C polymorphism and Alzheimer's disease susceptibility
}

\author{
Vandana Rai \\ Department of Biotechnovogy \\ V B S Purvanchal University \\ Jaunpur-222003,UP \\ Correspondence: raivandana@rediffmail.com
}

\begin{abstract}
:
Methylenetetrahydrofolate reductase (MTHFR) is a crucial enzyme involved in homocysteine/methionone metabolism. It catalyzes the conversion of 5,10methlenetetrahydrofolate in to 5methyltetrahydrofolate. A number of studies have examined the association of MTHFR A1298C polymorphism as risk factor for Alzheimer's disease (AD), but the results were contradictory. To clarify the influence of MTHFR A1298C polymorphism on Alzheimer's disease (AD), a meta-analysis of ten case-control studies was carried out. Four electronic databases were searched up to August, 2019 for suitable articles. The pooled odds ratios (ORs) with $95 \%$ confidence intervals (95\% CIs) were used to evaluate the association. All statistical analyses were performed by MetaAnalyst program.

The results of meta-analysis suggested that except allele contrast model, A1298C polymorphism is not risk for Alzheimer's disease using overall comparisons in three genetic models $(\mathrm{C}$ vs. $\mathrm{A}$ : $\mathrm{OR}=1.26,95 \% \mathrm{CI}=0.912-1.76, \mathrm{p}=0.04 ; \mathrm{CC}+\mathrm{AC}$ vs. $\mathrm{AA}$ : $\mathrm{OR}=1.43 ; 95 \% \mathrm{CI}=0.85-2.44 ; \mathrm{p}=0.05 ; \mathrm{CC}$ vs. $\mathrm{AA}: \mathrm{OR}=1.16,95 \% \mathrm{CI}=.88-1.55, \mathrm{p}=0.51 ; \mathrm{AC}$ vs. AA: $1.55 ; 95 \% \mathrm{CI}=0.81-$ 2.93, $\mathrm{p}=0.07$ ). Publication bias was absent in all five genetic models. In conclusion, results of present meta-analysis showed no significant association between MTHFR A1298C polymorphism and AD risk.
\end{abstract}

\section{Keywords:}

Alzheimer's disease, MTHFR, A1298C, Polymorphism

\section{Introduction:}

Alzheimer's disease (AD) is one of the major neurodegenerative diseases in elderly population. It is the most common form of dementia, affecting 1 in 8 individuals older than 60 years of age. Most AD cases are late in onset and are probably influenced by both genetic and environmental factors. Epidemiological studies have demonstrated that elevated levels of plasma homocysteine (Hcy) may play an important role in the pathogenesis of AD [1-3].

Folic acid/folate is essential for cellular methylation, DNA synthesis, and homocysteine metabolism. MTHFR and methionine synthase reductase (MTRR) are two important enzymes of folate pathway and dysfunction of these genes increases plasma homocysteine concentration [4,55). Both genes show polymorphism as MTHFR C677T, A1298C [6-9] and MTRR A66G [10-12] and frequency of these polymorphisms varies greatly word wide. MTHFR enzyme required for the conversion of 5,10-methylene-tetrahydrofolate to 5-methyltetrahydrofolate (5THF), 5THF is the methyl donor for synthesis of methionine from homocysteinine [13]. The MTHFR gene is present on short arm of chromosome 1 at position p36.3. MTHFR A1298C polymorphism is associated with reduced MTHFR enzyme activity and hyperhomocysteinemia [5].

In A1298C polymorphism, A is substituted with C nucleotide at position 1298 [5], leading to substitution of glutamate by alanine s (Glu429Ala) in the MTHFR enzyme. Glu429Ala in MTHFR enzyme, reduces $40 \%$ enzyme activity. Frequency of $1298 \mathrm{C}$ allele differs greatly in various ethnic groups of the world. The prevalence of the mutant CC homozygote variant genotype ranges from 7 to $12 \%$ in Europe, 4 to 5\% in Hispanics and 1 to $4 \%$ in Asian populations (1 to 4\%) [14]. Several studies have reported A1298Cpolymorphism as risk factor for several diseases like- cleft lip and palate, Down syndrome, neural tube defects, and psychiatric disorders etc [14]. MTHFR polymorphisms were studied as risk for $\mathrm{AD}$ by several researcher but their results were controversial. Hence, the aim of present meta-analysis was to conclude the role of MTHFR A1298C polymorphism in AD risk.

\section{Methods:}

Article search was carried out in electronic databases up to August, 2019 using key terms - MTHFR', 'A1298C', and 'Alzheimer's disease'. Criteria for inclusion of studies were as follows; (i) studies should be case-control association study; and (ii) the articles must report the sample size, distribution of alleles or genotypes for estimating the odds ratio (ORs) with 95\% confidence interval (CIs). Studies were excluded if one of the following existed: (i) case-only studies, and (ii) editorial, case reports or reviews. Meta- analysis was carried out according to the method of Rai et al [15] (.2014). Publication bias was calculated according to the method of Egger et al. [16] . All statistical analysis was done by MetaAnayst.

\section{Results:}

Total ten studies [17-26] were found suitable for the inclusion in the meta-analysis. In incuded ten studies number of cases was 1067and number of contro was 1527. The lowest sample size was 43 [23] and highest sample size was 
$162[20,21]$ in included studies (Table 1). Total cases genotype percentage of AA, AC and CC was 55.34\%, $44.65 \%$ and $11.84 \%$ respectively. The controls genotypes percentage of AA, AC and CC were $55.34 \%, 44.65 \%$ and $11.84 \%$ respectively.

Table 1. The distributions of MTHFR A1298C genotypes and allele number in Alzheimer's disease cases and controls

\begin{tabular}{|c|c|c|c|c|c|c|c|c|c|c|c|c|c|}
\hline \multirow[t]{2}{*}{ Study } & \multirow[t]{2}{*}{ Country } & \multirow[t]{2}{*}{$\begin{array}{l}\text { No. of } \\
\text { Case/Controls }\end{array}$} & \multicolumn{3}{|c|}{$\begin{array}{l}\text { Case } \\
\text { Genotypes }\end{array}$} & \multicolumn{3}{|c|}{$\begin{array}{l}\text { Control Allele } \\
\text { Genotypes }\end{array}$} & \multicolumn{2}{|c|}{$\begin{array}{l}\text { Allele } \\
\text { Case }\end{array}$} & \multicolumn{2}{|c|}{$\begin{array}{l}\text { Allele } \\
\text { Control } \\
\end{array}$} & \multirow{2}{*}{$\begin{array}{l}P \\
\text { value } \\
\text { HWE }\end{array}$} \\
\hline & & & $\mathrm{AA}$ & $\mathrm{AC}$ & $\mathrm{CC}$ & $\mathrm{AA}$ & $\mathrm{AC}$ & $\mathrm{CC}$ & $\mathrm{A}$ & $\mathrm{C}$ & $\mathrm{A}$ & $\mathrm{C}$ & \\
\hline Wakutani et al.,2002 & Japan & $241 / 352$ & 174 & 51 & 16 & 210 & 127 & 15 & 399 & 83 & 547 & 157 & 0.44 \\
\hline Bosco,2004 & Italy & $140 / 136$ & 69 & 67 & 16 & 59 & 61 & 16 & 205 & 99 & 179 & 93 & 0.96 \\
\hline Ravaglia et al.,2004 & Italy & $63 / 122$ & 26 & 18 & 4 & 52 & 63 & 7 & 70 & 26 & 167 & 77 & 0.03 \\
\hline Linnebank et al.,2004 & Germany & $162 / 169$ & 75 & 68 & 19 & 71 & 71 & 27 & 218 & 106 & 213 & 125 & 0.19 \\
\hline Anello et al., 2004 & Italy & $162 / 190$ & 83 & 78 & 19 & 82 & 89 & 19 & 244 & 116 & 253 & 127 & 0.46 \\
\hline Silva et al.,2006 & Brazil & $49 / 50$ & 21 & 21 & 1 & 27 & 22 & 1 & 63 & 23 & 76 & 24 & 0.14 \\
\hline Dorszewska et al., 2007 & Poland & $43 / 50$ & 13 & 18 & 7 & 21 & 23 & 6 & 44 & 32 & 65 & 35 & 0.93 \\
\hline Gledraltis et al.,2009 & Sweden & $92 / 238$ & 32 & 41 & 12 & 176 & 18 & 44 & 105 & 65 & 370 & 106 & 0 \\
\hline Mansoori et al.,2012 & India & $61 / 120$ & 20 & 41 & 19 & 44 & 59 & 17 & 81 & 79 & 147 & 93 & 0.69 \\
\hline Mansouri et al.,2013 & Tunisia & $38 / 100$ & 15 & 23 & 0 & 93 & 7 & 0 & 53 & 23 & 193 & 7 & 0.71 \\
\hline
\end{tabular}

In allele contrast ( $\mathrm{A}$ vs $\mathrm{C}$ ) meta-analysis, mutant $\mathrm{C}$ allele showed significant association with $\mathrm{AD}$ in random effect $(\mathrm{OR}=1.26,95 \% \mathrm{CI}=0.912-1.76, \mathrm{p}=0.04)$ models (Figure 1). Unlike to allele contrast meta-analysis, pooled odds ratio for homozygote genotype (CC vs. AA) did not show any association with $\mathrm{AD}$ adopting random $(\mathrm{OR}=1.16$, $95 \% \mathrm{CI}=.88-1.55, \mathrm{p}=0.51$ ) effect models. Association of mutant heterozygous genotype (AC vs. AA; co-dominant model) aso did not show any association with $\mathrm{AD}$ using random effect models $(\mathrm{OR}=1.55 ; 95 \% \mathrm{CI}=0.81-2.93)$. Dominant mutant genotypes $(\mathrm{CC}+\mathrm{AC}$ vs. $\mathrm{AA})$ showed no association with $\mathrm{AD}$ using random $(\mathrm{OR}=1.43 ; 95 \% \mathrm{CI}=$ 0.85-2.44; $\mathrm{p}=0.05$ ) effect models. Allele contrast cumulative meta-analysis showed that after inclusion of Gledraltis et al. [24] study, odds ratio increased to 1.029 and after then it increased to 1.26 (Figure 2). As evident by funnel plot the publication bias was not observed in any genetic model.

\section{Figure 1. Allele Contrast (A vs C) Random Effect Forest Pot of Ten Studies}

Figure 2. Allele Contrast Cumulative Meta-analysis

\section{Discussion:}

Results of present meta-analysis showed no association between MTHFR A1298C polymorphism and Alzheimer's disease. Elevated Hcy has been reported to be a risk factor for several psychiatric and neurodevelopmental disorders like neural tube defects, schizophrenia, bipolar disorder and depression. Hcy is implicated in increased oxidative stress, DNA damage, the triggering of apoptosis and excitotoxicity, all important mechanisms in neurodegeneration $[27,28]$.

Meta-analysis is a statistical tool, which is successfully used for the compilation of contradictory results of small effect/power case-control studies. Several meta-analysis were published which evaluated risk of small effect gene polymorphism for different disease and disorders like- epilepsy [29], Alzheimer's disease [30], G6PD [31], Down syndrome [32-34], Uterine Leiomyoma [35], orofacial cleft [36,37], depression [38], schizophrenia [39,40], autism [41, , male infertility [42] digestive tract cancer [43], lung cancer [44], endometrial cancer [45], breast cancer [46,47], prostate cancer [48], colorectal cancer [49], and esophageal cancer [50] etc.

Limitations of the study should be acknowledged like-(i) unadjusted crude OR is used, (ii) study number (only ten studies) and sample size are small, (iii) gene-gene or gene-environment interactions may modify the AD risk and; however, such stratified analysis could not be performed owing to lack of data.

\section{References:}

1. Fernandez, L.L., Scheibe, R.M. Is MTHFR polymorphism a risk factor for Alzheimer disease like APOE? Arq Neuropsiquiatr 63,1-6 (2005).

2. Wingo, T.S., Lah, J.J., Levey, A.I., et al. Autosomal recessive causes likely in early-onset Alzheimer disease. Arch Neurol. 69,59-64 (2012). 
3. Quadri, P., Fragiacomo, C., Pezzati, R., et al. Homocysteine, folate, and vitamin B-12 in mild cognitive impairment, Alzheimer disease, and vascular dementia. Am J Clin Nutr. 80,114-22 (2004).

4. Frosst, P., Blom, H.J., Milos, R., et al. A candidate genetic risk factor for vascular disease: A common mutation in methylenetetrahydrofolate reductase. Nat Genet 10, 111-113 (1995).

5. Weisberg, I., Tran, P., Christensen, B., et al. A second genetic polymorphism in methylenetetrahydrofolate reductase (MTHFR) associated with decreased enzyme activity. Mol Genet Metab. 64, 169-72 (1998).

6. Rai V, Yadav U, Kumar P, Yadav SK. Methyleletetrahydrofolate reductase polymorphism (C677T) in Muslim population of Eastern Uttar Pradesh, India. Ind J Med Sci. 64(5),219-23 (2010).

7. Rai, V., Yada, U. Kumar, P. Genotype Prevalence and Allele Frequencies of 5, 10-Methylenetetrahydrofolate Reductase (MTHFR) C677T Mutation in two Caste Groups of India. Cell Mol Biol. 58, OL1695- 701 (2012).

8. Rai, V., Yadav U, Kumar P. Prevalence of methylene tetrahydrofolate reductase C677T polymorphism in Eastern Uttar Pradesh. Indian J Hum Genet. 18(1), 43-46 (2012).

9. Yadav, U., Kumar, P., Gupta, S., Rai, V. Distribution of MTHFR C677T Gene Polymorphism in Healthy North Indian Population and an Updated Meta-analysis. Ind J Clin Biochem. 32(4),399-410 (2017).

10. Rai, V., Yadav, U., Kumar, P., Gupta, S. Methionine Synthase Reductase (MTRR) A66G Polymorphism in Rural Population of Uttar Pradesh (India). Biotechnology 10(2), 220-223 (2011).

11. Rai, V., Yadav, U., Kumar, P. MTRR A66G polymorphism in two caste groups of Uttar Pradesh (India). Indian J Med Sci. 66(5-6), 136-40 (2012).

12. Rai, V., Yadav, U., Kumar, P., Yadav, S.K. Analysis of methionine synthase reductase polymorphism (A66G) in Indian Muslim Population. Indian J Hum Genet. 19(2), 183-187 (2013).

13. Goyette, P., Pai, A., Milos, R., et al. Gene structure of human and mouse methylenetetrahydrofolate reductase (MTHFR). Mamm Genome. 9, 652-6 (1998).

14. Botto, L.D., Yang, Q. 5,10-Methylenetetrahydrofolate reductase gene variants and congenital anomalies: A HuGE review. Am J Epidemiol. 151,862-77 (2000).

15. Rai, V., Yadav, U., Kumar, P., et al. Maternal methylenetetrahydrofolate reductase C677T polymorphism and Down syndrome risk: A meta-analysis from 34 studies. Plos One 9 (9), e108552 (2014).

16. Egger, M., Dave Smith, G., Schneider, M., Minde, C. Bias in meta-analysis detected by a simple, graphical test. BMJ 315, 629-634 (1997).

17. Wakutani, Y., Kowa, H., Kusumi, M., et al. Genetic analysis of vascular factors in Alzheimer's disease. Ann N Y Acad Sci 977, 232-238 (2002).

18. Bosco, P. Association of IL-1 RN*2 allele and methionine synthase 2756 AA genotype with dementia severity of sporadic Alzheimer's disease. J Neurol Neurosurg Psychiatry. 75, 1036-1038 (2004).

19. Ravaglia, G., Forti, P., Maioli, F., et al. Common polymorphisms in methylenetetrahydrofolate reductase (MTHFR): relationships with plasma homocysteine concentrations and cognitive status in elderly northern italian subjects. Arch Gerontol Geriatr Suppl 9, 339-348 (2004).

20. Linnebank, M., Linnebank, A., Jeub, M., et al. Lack of genetic dispositions to hyperhomocysteinemia in Alzheimer disease. Am J Med Genet A 131,101-102 (2004).

21. Anello, G., Gueant-Rodriguez, R.M., Bosco, P., et al. Homocysteine and methylenetetrahydrofolate reductase polymorphism in Alzheimer's disease. Neuroreport 15, 859-861.

22. da Silva, V.C., Ramos, F.J., Freitas, E.M., et al. Alzheimer's disease in Brazilian elderly has a relation with homocysteine but not with MTHFR polymorphisms. Arq Neuropsiquiatr 64, 941-945 (2006).

23. Dorszewska, J., Florczak, J., Rozycka, A., et al. Oxidative DNA damage and level of thiols as related to polymorphisms of MTHFR, MTR, MTHFD1 in Alzheimer's and Parkinson's diseases. Acta Neurobiol Exp (Wars) 67,113-129 (2007).

24. Giedraitis, V., Kilander, L., Degerman-Gunnarsson, M., et al. Genetic analysis of Alzheimer's disease in the Uppsala longitudinal study of adult men. Dement. Geriatr Cogn Disord 27, :59-68 (2009).

25. Mansoo, N., Tripathi, M., Luthra, K, et al. MTHFR (677 and 1298) and IL-6-174 G/C genes in pathogenesis of Alzheimer's and vascular dementia and their epistatic interaction. Neurobiol Aging 33,1003 e1001-1008 (2012).

26. Mansouri L, Fekih-Mrissa N, Klai S, et al. Association of methylenetetrahydrofolate reductase polymorphisms with susceptibility to Alzheimer's disease, Clin Neurol Neurosurg 115, 1693-1696 (2013).

27. Mattson, M.P., Shea, T.B. Folate and homocysteien metabolism in neural plasticity and neurodegenerative disorders. Trends Neurosci. 26,137-46 (2003).

28. Sachdev, P.S. Homocysteine and brain atrophy. Prog Neuropsychopharmacol Biol Psychiatry 29,1152-61(2005).

29. Rai, V., Kumar, P. Methylenetetrahydrofolate reductase C677T polymorphism and susceptibility to epilepsy. Neurol Sci. 10.1007/s10072-018-3583-z (2018).

30. Rai, V. Folate pathway gene methylenetetrahydrofolate reductase C677T polymorphism and Alzheimer disease risk in Asian population. Indian J Clin Biochem 31,245-52 (2016).

31. Kumar, P., Yadav, U., Rai, V. Prevalence of glucose-6-phosphate dehydrogenase deficiency in India: an updated metaanalysis. Egypt J Med Hum Genet, 17, 295-302 (2016).

32. Rai, V. Polymorphism in folate metabolic pathway gene as maternal risk factor for Down syndrome. Int $\mathrm{J}$ Biol Med Res 2(4), 1055-1060 (2011).

33. Rai, V., Yadva, U., Kumar, P. Null association of maternal MTHFR A1298C polymorphism with Down syndrome pregnancy: An updated meta-analysis. Egypt J Med Hum Genet. 18, 9-18 (2017). 
34. Rai, V., Kumar, P. Fetal MTHFR C677T polymorphism confers no susceptibility to Down Syndrome: evidence from meta-analysis. Egyptian J Med Hum Genet. 19, 53-58 (2018).

35. Kumar, P., Rai, V. Catechol-O-Methyltransferase Val158Met polymorphism and susceptibility to Uterine Leiomyoma. Jacobs Journal of Gynecology and Obstetrics 5(1), 043 (2018).

36. Rai, V. Maternal methylenetetrahydrofolate reductase (MTHFR) gene A1298C polymorphism and risk of nonsyndromic Cleft lip and/or Palate (NSCL/P) in offspring: A meta-analysis. Asian J Med Sci. 6 (1), 16- 21 (2014).

37. Rai, V. Strong association of C677T polymorphism of methylenetetrahydrofolate reductase gene with nosyndromic cleft lip/palate (nsCL/P). Ind J Clin Biochem 33(1), 5-15 (2018).

38. Rai, V. Genetic polymorphisms of methylenetetrahydrofolate reductase (MTHFR) gene and susceptibility to depression in Asian population: a systematic meta-analysis. Cell Mol. Biol. 60 (3), 29-36 (2014).

39. Yadav, U., Kumar, P., Gupta, S., Rai, V. Role of MTHFR C677T gene polymorphism in the susceptibility of schizophrenia: An updated meta-analysis. Asian J Psychiatry 20, 41-51 (2016).

40. Rai, V., Yadav, U., Kumar, P., et al. Methylenetetrahydrofolate Reductase A1298C Genetic Variant and Risk of Schizophrenia: an updated meta-analysis. Indian J Med Res. 145(4), 437-447 (2017).

41. Rai, V., Kumar, P. Methylenetetrahydrofolate reductase A1298C Polymorphism and Autism susceptibility. Austin J Autism and Related Disabilities 4, 1048-1053 (2018).

42. Rai, V., Kumar, P. Methylenetetrahydrofolate reductase C677T polymorphism and risk of male infertility in Asian population. Indian J Clin Biochem 32(3), 253-60 (2017).

43. Yadav, U., Kumar, P., Rai, V. NQO1 Gene C609T Polymorphism (dbSNP: rs1800566) and Digestive Tract Cancer Risk: A Meta-Analysis. Nutr Cancer. 70(4), 557-568 (2018).

44. Rai, V. Folate Pathway Gene MTHFR C677T Polymorphism and Risk of Lung Cancer in Asian Populations. Asian Pac J Cancer Prev. 15 (21), 9259-9264 (2014).

45. Kumar, P., Singh, G., Rai, V. Evaluation of COMT Gene rs4680 Polymorphism as a Risk Factor for Endometrial Cancer. IJCB 10.1007/s12291-018-0799-x (2018).

46. Rai, V. Methylenetetrahydrofolate reductase A1298C polymorphism and breast cancer risk: a meta-analysis of 33 studies. Annals of Medical and Health Sciences Research 4 (6), 841-851 (2014).

47. Rai, V., Yadav, U., Kumar, P. Impact of catechol-O-methyltransferase Val 158Met (rs4680) polymorphism on breast cancer susceptibility in Asian population. Asian Pac J Cancer Prev. 18(5), 1243-50 (2017).

48. Yadav, U., Kumar, P., Rai, V. Role of MTHFR A1298C gene polymorphism in the etiology of prostate cancer: A systematic review and updated meta-analysis. Egyptian J Med Hum Genet 17, 141-148 (2016).

49. Rai, V. Evaluation of the MTHFR C677T Polymorphism as a Risk Factor for Colorectal Cancer in Asian Populations. Asian Pac J Cancer Prev 16 (18), 8093-8100 (2016).

50. Kumar, P., Rai, V. Methylenetetrahydrofolate reductase C677T polymorphism and risk of esophageal cancer: An updated meta-analysis. Egypt J Med Hum Genet 19(4),: 273-284 (2018). 


\section{Odds Ratio $95 \%$ Confidence Interval}

Study Name

Wakutani et al.,2002

Bosco et al.,2004

Ravaglia et al.,2004

Linnebank et al.,2004

662

Anello et al., 2004

Silva et al.,2006

Dorszewska et al., 2007

Gledraltis et al.,2009

Mansoori et al.,2012

Mansouri et al.,2013

Overall

N

576

340

740

186

176

646

400

276
1186

(n)

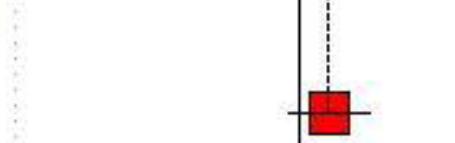

Confidence Interval

$0.725(0.539,0.974)$

$0.930(0.657,1.315)$

$0.806(0.477,1.362)$

$0.829(0.601,1.141)$

$0.947(0.697,1.287)$

$1.156(0.596,2.242)$

$1.351(0.731,2.494)$

$2.161(1.482,3.151)$

$1.542(1.029,2.310)$

$11.965(4.870,29.399)$

$1.267(0.911,1.763)$ 


\section{Cumulative Meta-Analysis}

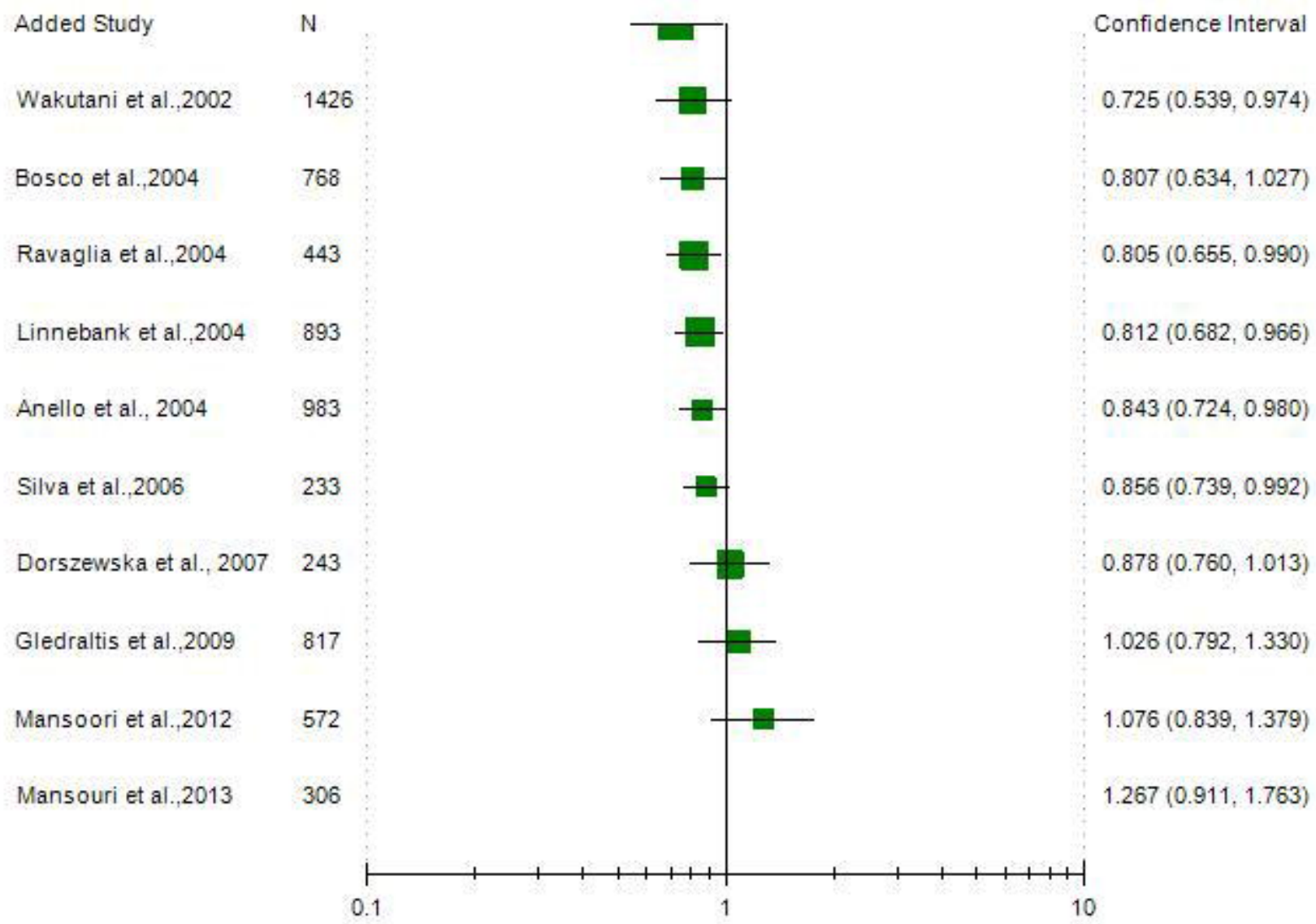

